\title{
Córdoba en boca de los universitarios uruguayos (algunos de sus cambiantes significados entre los años cincuenta y sesenta del siglo XX)
}

\author{
Córdoba in the voice of uruguayan University students. \\ Its ever-changing meanings \\ between the 50's and the 60's
}

\author{
Vania Markarian ${ }^{1}$ \\ Universidad de la República \\ vm119@caa.columbia.edu
}

(Uruguay)

\begin{abstract}
Resumen
A lo largo del siglo que nos separa del Manifiesto Liminar, los universitarios latinoamericanos han apelado incansablemente al legado de Córdoba como sustento de sus reclamos. Este artículo examina esta perdurable invocación en Uruguay en el período que va desde las luchas por una nueva Ley Orgánica para la Universidad de la República en los años cincuenta hasta la intervención de la institución por el gobierno autoritario instalado en 1973. En ese lapso, que es el que separa las esperanzas de cambio de la posguerra de la cancelación brutal del "nuevo autoritarismo" latinoamericano, las referencias al movimiento cordobés de 1918 fueron obligadas para más de una generación de universitarios que hoy podemos agrupar bajo el rótulo de "reformistas" en base a su recurrencia a esa misma apelación histórica. El análisis se centra en dos textos particularmente expresivos, uno de 1952 y otro de 1968, para destacar los cambiantes significados que el legado de Córdoba tuvo en esa etapa central para la lenta articulación y rápida frustración de un ambicioso plan de reforma estructural de la que era por entonces la única universidad del país.
\end{abstract}

Palabras Clave: universidad, Córdoba, Uruguay.

1. Agradezco los comentarios de María Caldelari, Fernando Devoto y los participantes del seminario interno del Archivo General de la Universidad de la República en 2017 (María Eugenia Jung, que lo coordinó, Evangelina Ucha, Lucía Secco, Lorena Garcia Mourelle, Lucas D’Avenia y Mariana Mendy). Vaya también mi agradecimiento a los lectores anónimos de esta revista y a los coordinadores del dossier. 


\begin{abstract}
The reference to the Liminar Manifesto has been central to the language of university actors in Latin America ever since it was issued by the students of the University of Córdoba in 1918. This paper analizes how students and faculty interpreted this seminal event in Uruguay in the struggles for a new statute for the Universidad de la República in the 1950s and until the intervention of the institution by the authoritarian government installed with the coup d' Etat of 1973. In these decades -between the hopeful climate of the post WWII period and its brutal abolition by the "new" Latin American authoritarianism- this language became central for generations of students and faculty members which aimed at transforming the structure and functions of their institution. Two basic texts, one from 1952 and one from 1968, are the ground of the analysis and show the ever-changing meanings of Córdoba's University Reform in the laborious articulation and swift annulment of this ambitious program of structural reform in the then only national university in the country.
\end{abstract}

Keywords: university, Córdoba, Uruguay.

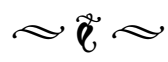

\section{Introducción}

A lo largo del siglo que nos separa del Manifiesto Liminar, los universitarios latinoamericanos han apelado incansablemente al legado de Córdoba como sustento de sus reclamos en las más diversas coyunturas. El mecanismo no sorprende: la construcción de una genealogía es una de las formas más básicas de legitimar posiciones sobre los problemas de cualquier presente y proyectar el futuro. No importa demasiado que ese ejercicio retrospectivo se asiente en un conocimiento profundo del pasado invocado. Después de todo, el trabajo de la memoria tiene siempre algo de anacrónico. Desde el punto de vista del análisis histórico, lo importante es desentrañar las formas particulares de relacionar historia, experiencia y expectativas en cada momento o lugar, es decir, ver cómo se construyen diferentes "regímenes de historicidad", para usar la feliz expresión de Francois Hartog
(2007). Siguiendo a Reinhardt Koselleck (1993), podemos decir también que el examen atento de la tensión que existe entre el campo de la experiencia y el horizonte de la espera de cualquier grupo social debe estar en el centro del trabajo historiográfico. En ese sentido, es importante recordar que la inscripción de algunos hechos como eventos históricos y su pervivencia en ciertas tradiciones de acción y pensamiento exigen un trabajo permanente de reinterpretación en el seno de los colectivos que los invocan.

Con estas ideas en mente, comencemos por señalar que el movimiento de Reforma Universitaria, surgido en la Universidad de Córdoba en 1918, adquirió rápidamente el poder de un mito para sucesivas generaciones de intelectuales de la región. En pocas palabras, podemos decir que este movimiento, fundamentalmente estudiantil, proclamó la necesidad de transformar el viejo modelo de las universidades 
latinoamericanas desde una perspectiva laica y atada a los valores democrático-liberales de los jóvenes Estados nacionales para convertirlas en espacios más abiertos a la movilidad social (Buchbinder, 2008). Su efecto se hizo patente rápidamente en fenómenos tan disímiles como la creación de la Alianza Popular Revolucionaria Americana (APRA) en Perú y el proceso fundacional de la Federación de Estudiantes Universitarios Uruguayos (FEUU), por nombrar dos ejemplos políticamente diversos y geográficamente dispares en los años veinte. ${ }^{2}$ No es el objetivo de este artículo, sin embargo, analizar el gran impacto de Córdoba en la política latinoamericana del siglo pasado.

Pretende, en cambio, mostrar su perdurable invocación por parte de diferentes actores universitarios uruguayos en el período que va desde las luchas por una nueva Ley Orgánica para la Universidad de la República en los años cincuenta hasta la intervención de la institución por el gobierno autoritario instalado en 1973. En ese lapso, que es el que separa las esperanzas de cambio de la posguerra de la cancelación brutal del "nuevo autoritarismo" latinoamericano, las referencias a Córdoba fueron obligadas para la formulación de las propuestas de cambio de más de una generación de universitarios que hoy podemos agrupar bajo el rótulo tal vez algo irónico de "reformistas" en base a su recurrencia a esa misma apelación histórica. Dejaré para el final una breve mención a lo que parecería una última declinación mordaz del apelativo. Me detendré primero en algunos ejemplos que permiten visualizar su potencia y, fundamentalmente, los cambiantes significados que la referencia al legado de Córdoba tuvo para los principales protagonistas de

2. Para Perú, ver, por ejemplo, Leandro Sessa (2011) y para Uruguay, Mark Van Aken (1990). la política universitaria en esos años. Prestaré especial atención a algunos textos que ilustran las sucesivas mutaciones que esa invocación sufrió en el proceso de lenta articulación y rápida frustración de un ambicioso plan de reforma estructural de la que era por entonces la única universidad del país. La selección no es completamente arbitraria: entre la profusión de menciones a Córdoba que ofrece la documentación universitaria del período, he elegido un puñado de ejemplos que me parecen particularmente elocuentes tanto por su formulación expresiva como por quienes los produjeron.

\section{Córdoba como "rémora" en las discusiones sobre la reforma de la Universidad}

Al comienzo del arco temporal que nos ocupa, a casi cuatro décadas del Manifiesto Liminar de los estudiantes cordobeses, esa propuesta (y aun su desglose) era fuente de inspiraciones diversas y reconocía múltiples interpretaciones. En Uruguay, en particular, las reivindicaciones que solían asociársele podían reclamar una tradición anterior a 1918. El incremento de las acciones sociales de la institución y la democratización de la vida universitaria, por ejemplo, habían sido banderas de los sectores estudiantiles que convocaron y organizaron el Primer Congreso Internacional de Estudiantes Americanos en Montevideo en 1908 (Van Aken, 1990, Oddone y París, 1971, Cuadro Cawen, 2018). En las décadas siguientes, las sucesivas modificaciones de la estructura y el gobierno de la Universidad de la República concretaron algunas de esas demandas mientras crecía el reclamo de un nuevo estatuto orgánico que las reuniera y consagrara de 
modo definitivo. A comienzos de los años cincuenta, al debatirse la inclusión del principio de autonomía integral de la Universidad en el proyecto de carta constitucional que debatía el parlamento nacional, ese reclamo encontró un contexto favorable (Petit Muñoz, 1971). Se aprobó entonces un texto que afirmaba ese principio en términos generales sin terminar de definir los aspectos financieros y con algunas incertidumbres relativas a los mecanismos vigentes de elección de autoridades. Estos elementos despertaron algunos focos de protesta y redoblaron los esfuerzos por afinar las definiciones estatutarias. A mediados de 1952, 1a Asamblea General del Claustro de la institución se reunió para retomar el trabajo sobre la nueva Ley Orgánica y produjo un anteproyecto que provocó intensas discusiones internas, fundamentalmente en torno al papel y la composición del Consejo Directivo Central, el porcentaje de estudiantes y profesores presentes en los órganos de conducción y el carácter resolutivo o consultivo del mismo Claustro (Markarian, Jung y Wschebor, 2008).

Ese fue el contexto para que la Asociación Uruguaya para el Progreso de la Ciencia (AUPC) publicara en 1952 un número de su revista enteramente dedicado a la nueva Ley Orgánica de la Universidad. La AUPC se había fundado cuatro años atrás al finalizar en Montevideo la Conferencia de Expertos Científicos de América Latina para el Desarrollo de la Ciencia, convocada por UNESCO, con la participación de los más destacados investigadores del momento y el propósito de fomentar la investigación científica a nivel local a tono con esfuerzos similares en la región (Martínez, 2001). A partir de entonces, su revista fue un foro principal para el debate de estos temas dentro del reducido círculo de académicos que entonces propugnaba la efectiva institucionalización 132 de esa actividad y proclamaba la necesidad de abandonar la orientación meramente profesionalista de la mayor casa de estudios del país. El redactor responsable era el ingeniero Óscar Maggiolo, destacado docente e investigador de la Facultad de Ingeniería y Ramas Anexas, quien publicó en ese número especial de 1952 tres artículos sobre temas que siguieron preocupándolo en las décadas siguientes: uno sobre la utilidad de construir un campus para favorecer el contacto diario entre los universitarios, otro sobre la perentoriedad de facilitar aspectos de gestión del equipamiento científico y un tercero titulado "Gobierno Universitario" con el que queremos iniciar este recorrido por los cambiantes usos de las apelaciones a Córdoba en Uruguay entre los años cincuenta y sesenta del siglo pasado. ${ }^{3}$

El texto comenzaba reconociendo que, por encima de las demandas que persistían a la interna de la institución, la Constitución de 1951 había consagrado "el principio rector del movimiento reformista latinoamericano iniciado en Córdoba en el año 1918", a saber: la participación estudiantil en el gobierno de la Universidad junto a docentes y egresados. Luego de recordar que en los hechos ya existía cierta representación estudiantil a través de diferentes mecanismos habilitados por el estatuto universitario vigente, el de 1908, Maggiolo procedía a explicar la necesidad de que la nueva Ley Orgánica avanzara decididamente sobre esas definiciones y modificara realmente las formas de gobierno y funcionamiento de la casa de estudios. Lo más importante, sostenía

3. Maggiolo, O. Ciudad universitaria, Aspectos prácticos que debe contemplar la Ley Orgánica de la Universidad y Gobierno universitario. Boletín de la Asociación Uruguaya para el Progreso de la Ciencia (Boletín), 1952/2. Archivo Laguardia (AL) (caja 57). Archivo general de la Universidad de La República (AGU). 
el ingeniero, era comprender la complejidad y especificidad de las funciones universitarias y, por lo tanto, dotarla de una serie de "comisiones técnicas especializadas" que pudieran asesorar a los consejos cogobernados sobre la diversidad de asuntos que caían bajo su égida. ${ }^{4}$

Llegado a este punto, que era el centro de su argumento en este texto, el autor volvía a recurrir a Córdoba, ahora como demostración negativa de los límites del movimiento que reconocía allí su origen para llevar adelante estas tareas. Transcribo en extenso su defensa de la urgencia de especializarse en el manejo de los asuntos universitarios para que se perciba su virulencia frente a la recuperación acrítica del mismo legado que había comenzado elogiando:

Este nuevo principio del gobierno universitario es el que debe sustituir al "dogma" reformista que afirma que todos los males universitarios se deben a las camarillas de personas inescrupulosas que se apoderan de las Casas de estudio para explotarlas en su propio beneficio y que la única solución es integrar los Consejos con delegados de los estudiantes que todo lo van a arreglar. Sostener esto hoy día, luego de treinta y cuatro años del ejercicio de la Reforma Universitaria, es tan tonto y evidencia tal falta de miras como aquéllos que en el propio año 18 no supieron ver en aquel movimiento realmente revolucionario un germen de transformación, que si no se hubiera convertido en dogma podría haber transformado radicalmente las universidades latinoamericanas. Lo malo de las ideas revolucionarias es que la luz de las mismas encandila a los topos, y éstos en su ceguera sólo saben repetirla convirtiendo lo que pudo ser un foco de in-

4. Maggiolo, O. Gobierno universitario. Boletín, 1952/2, p. 23. usitado progreso en una rémora que estanca al cabo de los años toda nueva iniciativa de posible progreso. ${ }^{5}$

Esta argumentación intervenía en uno de los puntos álgidos del debate contemporáneo sobre la integración de los diferentes órdenes en el cogobierno: la proporción de estudiantes. Ante un movimiento estudiantil que reclamaba representación paritaria con los docentes, Maggiolo sostenía que estos últimos, por ser quienes mejor conocían la vida universitaria y más permanecían en su seno, debían triplicar en peso a cada uno de los otros órdenes en una proporción de seis, dos y dos. En ese sentido, su alegato por una "forma ejecutiva" de manejar la institución no implicaba una defensa de supuestos especialistas en gestión en base a un principio de eficiencia tecnocrática sino que apuntaba a un fortalecimiento del poder de los docentes en los procesos de decisión. La preocupación central que subyacía a este planteo formal era cómo cumplir con los fines sociales de la universidad, otro de los postulados emanados de la tradición cordobesa, precisando que ésta debía "acercarse al pueblo" desde la especificidad de sus funciones, es decir, "por el camino de resolverle sus problemas en los laboratorios" y mediante "la preparación de técnicos profesionales". ${ }^{6}$

Para avanzar en ese camino, continuaba Maggiolo, los ejemplos debían buscarse "en las grandes universidades extranjeras, en esas mismas universidades cuya organización no queremos copiar pero que (...) gustamos citar que hemos visitado en nuestros viajes de estudio". Abogaba por superar "nuestro cerrado espíritu

5. Maggiolo, O. Gobierno universitario, Boletín, 1952/2, pp. 24-25.

6. Maggiolo, O. Gobierno universitario, Boletín, 1952/2, p. 25. 
regionalista" para reconocer que en las tres décadas transcurridas desde la "Reforma Universitaria, las Universidades que la han adoptado no han aportado un ápice al progreso cultural de la humanidad." No admitir esto, argumentaba finalmente, era adscribirse a "una tendencia reaccionaria", quedarse en la "posición (...) más cómoda y (...) más sencilla” y convertir "lo que fue revolucionario en rémora insoportable". ${ }^{7}$ Es interesante notar cómo en la pluma de este destacado docente la discusión sobre la configuración del gobierno universitario local se desplazaba rápidamente hacia la presentación entusiasta, a pesar del dejo irónico, de los modelos de universidad que ponían a la actividad científica como centro de sus estructuras y formas de funcionamiento.

Poco más de un lustro más tarde, las enconadas discusiones que este texto permite vislumbrar se saldaron, al menos transitoriamente, en las provisiones de la Ley Orgánica de 1958, aunque sin terminar de resolverse el tema de fondo relativo a la organización académica que mantenía incambiada la estructura federal de facultades sancionada en el estatuto de 1908, con gran peso de las corporaciones profesionales. Por un lado, se acordó una representación de cinco docentes, tres egresados y tres estudiantes en los consejos, a medio camino entre las demandas estudiantiles y las propuestas de vastos grupos de docentes entre los que se encontraba Maggiolo; por otro, se tomó una definición amplia de los fines esenciales de la Universidad, que incluía de hecho las tareas de extensión e investigación, algo que hoy puede resultar obvio pero que contravenía un siglo de fuerte inclinación profesionalista en la casa de estudios (con la única excepción de la Facultad

7. Maggiolo, O. Gobierno universitario, Boletín, 1952/2, pp. 25-6.

134 de Humanidades y Ciencias fundada en 1945). En este último sentido, la consagración de la nueva ley dejaba abierta una agenda de acción en el futuro inmediato, especialmente en torno a la necesidad de definir una estructura adecuada al ejercicio de todas las funciones que le asignaba a la institución.

Efectivamente, en esa misma época, una serie de innovaciones institucionales realizadas durante el rectorado de Mario Cassinoni (19561964) auguró la voluntad de realizar esfuerzos sistemáticos por mejorar la gestión y fortalecer el cumplimiento de los nuevos objetivos de la Universidad. Se tomaron, entonces, medidas tan diversas como la restructura de áreas enteras de la administración, la creación de servicios académicos, la actualización de planes de estudio, la apertura de nuevas carreras, el fomento de la actividad científica y la formalización de las tareas de asistencia y extensión (Markarian, Jung y Wschebor, 2008). También se trató de mejorar la política de comunicación y se comenzó a editar la Gaceta de la Universidad, una publicación oficial que difundía las actividades académicas y daba a conocer la opinión de los principales actores universitarios comprometidos con el proceso de renovación. Resulta por tanto interesante resaltar que el primer editorial de esta revista se acercaba al planteo de docentes como Maggiolo al reconocer que el "gran movimiento de la Reforma nos condujo a una maduración rápida y a un prestigio indiscutible en el concierto latinoamericano. Pero ese movimiento disminuyó su marcha y hoy (...) somos menos prestigiosos y significamos menos en un mundo que se renueva vertiginosamente". ${ }^{8}$

8. Editorial (1 de agosto de 1957). Gaceta de la Universidad. AGU. 
La concreción de los planes de cambio de Cassinoni y las luchas por la aprobación de la Ley Orgánica tal como venía de la Universidad, prácticamente sin intervención de los parlamentarios, fueron en gran medida el resultado de la decidida movilización estudiantil. Estas luchas mostraron a la FEUU como un actor relevante de la política nacional en alianza con algunos sectores obreros que aprovecharon el año electoral para redoblar sus reclamos en un clima de aumento de la protesta y la conciencia del agotamiento de un modelo de país. Al comenzar esta etapa, en la FEUU prevalecían las corrientes anarquistas y predominaba una orientación "tercerista" frente a las dos principales potencias que polarizaban el conflicto global. El triunfo de la revolución en Cuba propició una nueva hegemonía de cuño marxista a partir de la alianza entre socialistas y comunistas (Van Aken, 1990, p. 174). A su vez, el ingreso formal al cogobierno incorporó nuevas tensiones entre los militantes estudiantiles y en su relación con otros actores universitarios: mientras algunos criticaban a la Federación por su excesivo involucramiento en temas administrativos, sosteniendo que la vida gremial se había burocratizado sin lograr cambiar sustancialmente la orientación de la institución, muchos docentes y otras autoridades le reclamaban moderar sus reclamos en nombre de la responsabilidad que ahora compartían como miembros plenos de la dirección de la casa de estudios. $^{9}$

9. Una serie de artículos aparecida en el semanario Marcha entre fines de 1964 y comienzos de 1965 permite hacerse una idea de estas posiciones. Ver, por ejemplo:

A cinco años, primer balance: Los estudiantes en el gobierno de la Universidad. (11 de diciembre de 1964), Adición y no cambio: Los estudiantes en el gobierno de la Universidad. (24 de diciembre de 1964) Marcha (Ma) y La enfermedad y sus causas: Los estudiantes en el gobierno de la Universidad. (22 de enero de 1965). Ma. AGU.
Al mismo tiempo, en 1958, por primera vez en casi cien años, el Partido Nacional (o Blanco) ganó las elecciones nacionales. La coincidencia de la rotación de partidos en el gobierno y el cambio de estatuto universitario significó una transformación sustancial en las relaciones entre la institución y el poder político. Quizás el conflicto más notorio durante los dos gobiernos colegiados blancos giró en torno a la creación de un organismo dedicado al fomento de la ciencia y tecnología por fuera de la órbita universitaria (de corto alcance y escasas realizaciones en este tramo) (Jung, 2013a). Al mismo tiempo, el Poder Ejecutivo emprendió un camino de ajuste económico basado en los lineamientos del Fondo Monetario Internacional con recortes presupuestales endémicos y se trató de introducir mecanismos de evaluación y planificación que permitieran recibir fondos para diversos programas públicos a través de la Alianza para el Progreso (como la recordada Comisión de Inversiones y Desarrollo Económico, CIDE). De esta manera volvió a sentirse en Uruguay el renovado impacto de la Guerra Fría, con Estados Unidos tratando por todos los medios de debilitar la influencia de la triunfante Revolución Cubana. En este contexto se manifestaron especialmente en los ámbitos universitarios los embates de las derechas que comenzaron por criticar la masificación estudiantil y el giro a la izquierda de grandes sectores intelectuales y terminaron por caracterizar a la institución en su conjunto como "enemigo interno", pidiendo la creación de alternativas privadas y reclamando su intervención desde finales de los sesenta (Jung, 2013b). 


\section{El regreso de Córdoba en boca de una generación militante}

En este clima, en medio de adaptaciones a las nuevas formas de funcionamiento interno y desajustes con un sistema político cada vez más hostil, se fue consolidando en el gobierno universitario una generación que, habiendo promovido la Ley Orgánica de 1958, tenía como agenda pendiente la modificación de la estructura de la institución y su forma de llevar adelante sus funciones básicas, con especial preocupación por el lugar de la investigación científica y sus repercusiones sociales. A pesar de las realizaciones del periodo de Cassinoni, predominaba en estos universitarios la sensación de que poco se había avanzado en esa dirección. La elección de Óscar Maggiolo como rector en 1966, con apoyo de amplios sectores estudiantiles y docentes, afianzó esas aspiraciones de cambio. La coyuntura política nacional también pareció propicia para formalizar un plan concreto de reforma. A mediados de 1967, el rector Maggiolo presentó un documento que, articulado como un pedido de partidas presupuestales al gobierno central, aprovechaba la oportunidad que ofrecían los instrumentos de planificación del Poder Ejecutivo previstos en la nueva Constitución (bajo el influjo de la CIDE) y la disposición del flamante presidente colorado, Óscar Gestido, al diálogo con la Universidad luego de los períodos de enfrentamiento de los colegiados blancos (Markarian, 2011).

El llamado "Plan Maggiolo" tenía como eje la transformación de la estructura federada en base a facultades pensadas y establecidas para el ejercicio liberal de las diferentes profesiones. Esto implicaba una organización alternativa en institutos centrales con la función primordial de la investigación en estrecha coordina- ción con la enseñanza y una concepción amplia de las tareas de extensión. Junto con esto, se pensaba crear una facultad de educación y promover la integración con el resto del sistema educativo. Otras medidas, como un programa de becas para estudios de posgrado en el extranjero y la unificación de algunos servicios y funciones para evitar la duplicación del gasto, completaban una propuesta sintética de cambio institucional. Sin entrar en un análisis exhaustivo, vale la pena destacar que el documento se detenía largamente en la construcción de su legitimidad histórica a partir de la idea de un presente de crisis que debía buscar en el pasado las claves de su resolución en base a lo que se postulaba como una suerte de tradición nacional de apelar a la inversión en educación para salir de épocas difíciles. No mencionaba ni una sola vez a Córdoba en sus argumentaciones, volviendo a poner de manifiesto hasta qué punto la referencia se había disociado del programa transformador preconizado por la generación que ahora dominaba el gobierno universitario (Maggiolo, 2017).

Apurémonos a decir que el plan enfrentó enseguida una serie de frenos externos que fueron determinantes en su fracaso: el mensaje presupuestal del Poder Ejecutivo asignó a la institución la mitad de lo solicitado y, antes de terminar el año, el notorio giro autoritario del gobierno, con la asunción de Jorge Pacheco Areco en lugar del fallecido Gestido, vino a completar un panorama poco alentador para cualquier intento de cambio. A partir de entonces, el gobierno recurrió de modo casi permanente a las llamadas "Medidas Prontas de Seguridad", una forma limitada del estado de sitio prevista en la Constitución, desmantelando los anteriores mecanismos de lidiar con el conflicto social y asumiendo una actitud cada vez más abiertamente represiva. Antes de re- 
pasar los efectos de esta reorientación gubernamental en los debates universitarios, me interesa apuntar que los frenos internos también coadyuvaron a que la propuesta de reforma integral presentada por Maggiolo naufragara en medio de complejas negociaciones y resistencias producto tanto de divergencias sobre cómo modificar la vida universitaria como de actitudes corporativas y defensivas de posiciones de poder relacionadas con las formas de gobierno establecidas por la Ley Orgánica de 1958 (y antes).

A su vez, aunque los primeros informes de los organismos especializados de la FEUU se apresuraban a elogiar la propuesta de $\mathrm{Ma}$ ggiolo y trataban de mostrar su continuidad con anteriores posturas gremiales, pronto fue evidente que las posiciones internas eran muy diversas e incluían crecientes sectores que se oponían a "la posibilidad de un desarrollo de la Universidad, la investigación y las ciencias" que no estuviera condicionada "a una previa transformación de la sociedad en sus estructuras fundamentales. ${ }^{10}$ Esto apuntaba directamente contra la inspiración que podríamos llamar "desarrollista" presente en el plan desde su origen en los planteos de la CIDE hasta su uso de las herramientas de la planificación indicativa y la profunda convicción de que la educación era un motor primordial del cambio social. En los documentos estudiantiles se presentaba esa tendencia entonces en boga en amplios círculos académicos y de gobierno como el perfecto negativo de cualquier posibilidad de cambio social radical. En poca palabras, digamos que estas voces construían sus posturas en base a una presentación esquemática de escuelas de pensamiento que estaban entonces en disputa

10. Plan Maggiolo: ¿Una propuesta de entrega? Cuadernos del Militante 1, 1967, pp. 6-8, Archivo Wschebor, AGU. $\mathrm{y}$ abiertas a diferentes interpretaciones (y con las que las autoridades universitarias tenían también una relación frecuentemente ambigua, según ejemplifican las propias posiciones de Maggiolo frente al trabajo de la CIDE en materia de educación). ${ }^{11}$

En medio de estas y otras discusiones sobre temas nacionales, regionales y globales que resulta imposible reseñar aquí, se fue imponiendo en el movimiento estudiantil una inclinación general hacia la radicalización de las posiciones y la escalada de las estrategias de lucha. En la segunda mitad de los sesenta, mientras el país se adentraba en una crisis social y política sin precedentes, fueron creciendo los sectores, en un comienzo relativamente inorgánicos y con poca capacidad de incidencia, que disputaban desde la izquierda con la anterior alianza de comunistas y socialistas por el control del movimiento con apelaciones a la acción directa que muchas veces los acercaron a los viejos núcleos anarquistas predominantes hasta fines de los cincuenta.

Todavía en 1967, representantes de esas diferentes tendencias participaron junto a docentes y egresados de un concurrido seminario extra curricular en torno a la idea de la "universidad latinoamericana” como tradición y horizonte de lucha que dirigió el antropólogo y educador brasileño Darcy Ribeiro, exiliado en Montevideo luego de que el golpe de Estado en su país truncara la experiencia pionera de la Universidad de Brasilia (Ribeiro Coelho, 2002). No parece arriesgado afirmar que en el planteo de Ribeiro la mención a Córdoba era secundaria,

11. Ver por ejemplo Maggiolo, O. (28 de enero de 1966). Universidad y CIDE: Una tesis colonialista del desarrollo. $M a$, pp. 6-7 y 22. Sobre el trabajo de la CIDE y la participación de los universitarios, ver Adolfo Garcé (2002). 
aunque se la señalaba como el "punto más alto" de "un movimiento de reforma" que "inspiró algunas innovaciones importantes" en la organización de las universidades del continente. El nudo conceptual de su propuesta de "una nueva universidad" (o "la universidad necesaria”) para América Latina era la exhortación a superar la tensión entre el papel de las instituciones del conocimiento en la "preservación de la estructura social vigente" y su posible contribución a procesos de cambio que no fueran meramente "modernizadores". En ese camino, como sostuvo repetidamente el brasileño frente a numerosas audiencias en las diversas ciudades de su exilio en los años sesenta y setenta, no había modelos claros a imitar ya que las universidades estaban en crisis a lo largo y ancho del globo. Era hora, por tanto, de buscar soluciones propias, acordes con un camino de autonomía de los países latinoamericanos ( $\mathrm{Ri}-$ beiro, 1968).

Ese marco conceptual fue influyente en muchos universitarios uruguayos de la época de diversas inclinaciones académicas y políticas, incluyendo el círculo cercano al rector Maggiolo en momentos de la formulación de su plan, que coincidió con el seminario antes mencionado en la primera mitad de 1967. En el caso de los militantes estudiantiles, la participación en esas instancias expresó un sostenido compromiso con la reestructura de la institución, al tiempo que el tono de sus intervenciones en ese y otros ámbitos comenzaba a articular una nueva forma de entender los alcances de la política universitaria. Para grandes sectores se trataba, como afirmó el estudiante de la Facultad de Humanidades Marcos Lijstenstein al reseñar ese mismo seminario en Marcha, de tomar partido frente a las "dos fidelidades" de las instituciones de educación superior: a las "necesidades del desarrollo nacional", que ahora sólo parecían alcanzables mediante el cambio revolucionario, y a los "altos patrones internacionales del saber", que ahora resultaban incompatibles con las primeras. ${ }^{12}$ Las denuncias de las intervenciones del gobierno de Estados Unidos en materia cultural estaban en el corazón de estas posturas, con copiosas referencias a los recientes antecedentes nacionales y regionales al respecto. ${ }^{13}$

Así, grupos importantes del movimiento estudiantil, más rápido y más claramente que otros actores universitarios, fueron definiendo un programa de lucha que solía subordinar el abordaje de la problemática académica a sus posiciones sobre una situación nacional e internacional que demandaba cada vez más atención y compromiso. Grandes contingentes de jóvenes militantes radicalizados se fueron acercando a las estructuras orgánicas de la izquierda política, incluyendo los grupos de la llamada "nueva izquierda" que preconizaban o practicaban la lucha armada, y coordinaron sus acciones para imprimir su orientación a las movilizaciones. La irrupción de los estudiantes en las calles de Montevideo en 1968 mostró claramente estas disputas y también el afianzamiento de modos de acción cada vez más confrontacionales en todo el espectro de las izquierdas, incluyendo a los comunistas, que tradicionalmente habían respetado los límites legales de la protesta (Markarian, 2012). En ese contexto, fueron cambiando dentro del colectivo universitario los significados asignados a conceptos de gran circulación y aparente aceptación unánime como "cogobierno" y "au-

12. Marcos Lijsteinstein (23 de junio de 1967). La Universidad en tela de juicio. $M a$.

13.Estos antecedentes referían generalmente a proyectos de ciencias sociales financiados desde Estados Unidos. Al respecto: Petra (2008-9) y Markarian (2016). 
tonomía", fuertemente asociados a la tradición reformista que remontaba sus orígenes a Córdoba, con sectores crecientes que los veían como herramientas perimidas en una situación política que empezaban caracterizar como de inminencia revolucionaria.

Sin embargo, es interesante destacar, para ir cerrando el círculo de estas reflexiones sobre la presencia de esa tradición en el discurso de los actores universitarios uruguayos de la época, que las apelaciones a Córdoba adquirieron entonces un nuevo vigor y significado en boca de muchos dirigentes de la FEUU. Como suele ocurrir con las interpretaciones de hechos históricos y mitos fundantes, la novedad no era total: se recuperaba un sentido latente en el elemento "juvenilista" que tanto se ha señalado en relación a la revuelta cordobesa y su papel en la forja de un discurso antiimperialista de alcance continental. ${ }^{14}$ Las invocaciones a 1918 para llamar a la revuelta o a la protesta habían sido recurrentes en el movimiento estudiantil uruguayo durante las décadas transcurridas desde entonces y seguían siéndolo en los sesenta. A fines de 1966, por ejemplo, en medio de una discusión sobre asuntos primordialmente académicos de la Facultad de Ingeniería y Agrimensura, el delegado del ala comunista al Consejo Directivo Central, Horacio Bazzano, había citado del Manifiesto Liminar el "derecho sagrado a la insurrección" para los estudiantes de esa facultad. ${ }^{15}$

14. Sobre el impacto de Córdoba entre el "juvenilismo rodoniano", que básicamente asociaba la juventud a la emergencia de lo nuevo, y las versiones más ideológicas, ya cargadas de sentidos de lucha antiimperialista para una “nueva generación”, véase: Beigel (2006).

15. Consejo Central Universitario (CCU), Actas de Sesiones (AS), 17 de diciembre de 1966, AGU, Montevideo.
Pero quiero tomar un texto de fines de 1968 para ejemplificar mejor las implicancias de este nuevo giro. El número 32 de la revista del Centro de Estudiantes de Arquitectura (en adelante, CEDA), afiliado a la Federación, apareció durante la suspensión de clases decretada por el Poder Ejecutivo en setiembre, medida que pareció en principio eficaz para contener la protesta juvenil pero que en realidad propició su canalización en estructuras políticas orgánicas de posiciones cada vez más radicales. Una gran parte de la revista estaba dedicada a la arquitectura escolar con sendos artículos técnicos e históricos sobre estos temas, además de diversas contribuciones sobre diferentes aspectos arquitectónicos y otras de interés cultural general, según el formato usual de este tipo de publicaciones en la Universidad. ${ }^{16}$

Sus páginas se abrían, no obstante, con un editorial que no contenía una sola palabra sobre esos asuntos sino que se concentraba en explicar la necesidad de redoblar las medidas de lucha al terminar uno de los años más violentos en la historia política reciente del país. Primero se incluía una dedicatoria a los tres estudiantes muertos por la policía en las calles de Montevideo en agosto y setiembre de 1968. A continuación, se recordaba la situación de la Universidad de La Habana en vísperas del derrocamiento del dictador Fulgencio Batista para afirmar que "la nueva Universidad, nacida en Córdoba en 1918, se había extendido por todo el continente y mostraba en todos los rincones de la región la fuerza incontenible de un movimiento llamado a desafiar las bases

16. Véase: (diciembre de 1968). Revista del Centro de Estudiantes de Arquitectura (CEDA) 32. Agradezco a Pedro Barrán que me facilitó una reproducción de esta revista proveniente de la biblioteca de la Facultad de Arquitectura, Diseño y Urbanismo, Universidad de la República, Montevideo. 
de un régimen de injusticia y sometimiento, en su propio seno". La autonomía universitaria encarnaba esta contradicción, proseguía el editorial, porque daba a los estudiantes y a los intelectuales la posibilidad de cuestionar a las clases dominantes desde adentro de la institución. Pero tarde o temprano, se concluía, esta contradicción estallaba, como había sucedido en Cuba casi diez años atrás y como estaba ocurriendo en esos meses en Uruguay. Siguiendo este razonamiento, el escrito terminaba con una nueva apelación histórica para explicar los orígenes de esa contradicción y alentar a su superación: "Hoy, noviembre de 1968, a cincuenta años de la Reforma de Córdoba y a diez del logro de la Ley Orgánica de nuestra Universidad, los estudiantes uruguayos comenzamos una nueva etapa, más dura y comprometida, la de la lucha libertadora." 17

El número de la revista del CEDA se cerraba con un extenso discurso del Che Guevara en el Primer Encuentro Internacional de Profesores y Estudiantes de Arquitectura celebrado en La Habana en 1963. En esa ocasión, el líder guerrillero había llamado a considerar todo conocimiento técnico un arma a disposición de intereses políticos y conminado a profesionales e intelectuales a poner sus esfuerzos al servicio de la revolución y, en última instancia, de "esa sociedad con la que nosotros soñamos (...) el comunismo" ${ }^{18}$ Un ejercicio de anticipación histórica nos permite ubicar mejor estas referencias dado que varios de los miembros de la comisión directiva del CEDA integraban entonces la Agrupación Revolucionaria Estudiantil de Arquitectura (en adelante, AREA 3) y tuvieron luego destacada actuación en el Movimiento de Liberación Nacional-Tupa-

17.(diciembre de 1968). CEDA 32, pp. 3-6.

18.(diciembre de 1968). CEDA 32, pp. 83-90.

140 maros (en adelante, MLN-T), el grupo guerrillero más importante de Uruguay en los próximos años, todavía muy reducido en números y poco conocido a fines de $1968 .^{19}$

Si evitamos adelantarnos y volvemos a la política universitaria de la época, lo cierto es que, como obertura y colofón del contenido de una revista típicamente estudiantil, el editorial antes citado y este discurso de Guevara mostraban la efectiva voluntad de algunos sectores de politizar al extremo el quehacer académico y terciar en la polémica sobre cuál era la función primordial de las instituciones del conocimiento y cuáles los obstáculos para su efectiva realización. Hilando una historia que se leía en clave latinoamericana y antiimperialista, la alusión a Córdoba permitía a los militantes estudiantiles resignificar los contenidos básicos de la tradición reformista: el cogobierno, la autonomía y, fundamentalmente, el compromiso social que se asimilaba ahora con la lucha revolucionaria. Es claro que esta clave de lectura entró pronto en conflicto con aquellos que privilegiaban las funciones específicas de investigación y docencia en tanto formas esenciales de la acción social de las universidades, como Maggiolo en el texto con el que abrimos este análisis.

No es menos cierto que el ajuste autoritario del gobierno, especialmente a partir de 1968, con el allanamiento de los locales universitarios, la represión violenta de la protesta y el extremo del asesinato de estudiantes, movió a grandes contingentes, no sólo juveniles, hacia posiciones de disidencia política. Maggiolo, por ejemplo, empezó el período en el ala progresista del

19. Entre los listados en la ficha técnica de la revista, Jesús Arguiñarena, Américo Rocco y Lucía Topolanski pertenecían a AREA 3 y fueron luego destacados militantes del MLN-T (Rey Tristán, 2006). 
Partido Colorado, adhiriendo al papel social del Estado desde una posición liberal que miraba a Europa como faro de la civilización, y terminó encabezando el movimiento de protesta contra el gobierno del también colorado Jorge Pacheco Areco a fines de 1967, a poco de haber presentado su ambicioso plan de reforma. ${ }^{20}$ Ya en marzo de 1968, en sus palabras de apertura al seminario "Por una política cultural autónoma para América Latina”, recordó que "esta reunión está convocada por una de las pocas Universidades de América en la cual se practica en los hechos las ideas proclamadas por los hombres de Córdoba, hace exactamente medio siglo." Lo que tres lustros atrás era una "rémora" para la efectiva actualización de la vida académica aparecía ahora como un legado valioso que estaba en riesgo inminente en la nueva situación regional. ${ }^{21}$

Pocos meses después, al defender las acciones de la institución (y su gestión al frente de la misma), sostuvo que "no es una casualidad que toda vez que se comienza a edificar una Universidad o un Centro Científico en Latinoamérica, que pone énfasis en el desarrollo de las ciencias básicas, se le destruye bajo pretexto de ser centro de subversión." ${ }^{22}$ Este pesimismo se alimentaba tanto de los repetidos ataques del gobierno a la Udelar como de las experiencias

20. Su actividad pública de oposición al autoritarismo de Pacheco se hizo aún más notoria al integrarse al Movimiento Nacional de Defensa de las Libertades Públicas junto con otras personalidades y representantes de organizaciones sociales, políticas y religiosas.

Este movimiento realizó su primer acto público en la Universidad a fines de 1967. Ver CCU, AS, 27 de diciembre de 1967.

21. Palabras de apertura de Maggiolo, véase: Bagú (1970, pp. 12-13).

22. Maggiolo: Ellos decretaron la violencia. 4 de octubre de 1968. $M$. recientes de la región, especialmente el brutal desmantelamiento de la Facultad de Ciencias Exactas y Naturales de la Universidad de Buenos Aires en 1966, que había traído a muchos científicos a estas costas donde tanto contribuyeron a la renovación de diversas ramas del conocimiento como a advertir sobre el accionar autoritario en los centros académicos. ${ }^{23}$

Sin embargo, ni Maggiolo ni sus colegas que habían bregado por la actualización de la vida académica en Uruguay desde sus primeras acciones conjuntas en la AUPC, abandonaron la defensa de la autonomía universitaria con respecto al poder político como única garantía de la actividad intelectual en sentido amplio. Enfrentados a varios intentos de regular los mecanismos de gobierno de la Udelar mediante la implantación del voto secreto y la creación de organismos coordinadores de la enseñanza bajo control del Ejecutivo, estos universitarios siguieron defendiendo la práctica específica de la investigación científica porque "contribuye a formar una conciencia proclive al cambio de fondo", como puntualizó Maggiolo en el seminario de 1968. ${ }^{24}$ Esa sostenida confianza en el papel de las instituciones del conocimiento como promotoras del cambio social trazó una línea divisoria con varios de quienes los habían acompañado en su brega reformista hasta la culminación de su formulación en el "Plan Maggiolo". He analizado en otra parte el involucramiento de los comunistas en estos debates, especialmente a partir de la figura del matemático José Luis Massera, muy cercano a Maggiolo desde sus comienzos en la Facultad

23. Véase por ejemplo la intervención el astrofísico argentino Carlos Varsavsky y la lista de participantes en el seminario recién mencionado en Bagú (1970,pp. 94 y 142-143).

24. Intervención de Maggiolo en Bagú (1970, p. 94). 
de Ingeniería y Ramas Anexas, y su forma de entender la participación de los intelectuales y las alianzas de clase en los procesos de cambio social (Markarian, 2014-15). Me interesa ahora mostrar, en cambio, el papel de quienes descreyeron de los espacios de construcción institucional y optaron por otros caminos para su militancia. Para ellos, ya en 1968, las preocupaciones académicas y hasta la defensa de la autonomía habían dejado de ser de "por sí un objetivo revolucionario". ${ }^{25}$

Este tránsito ha sido descrito con precisión por Claudia Gilman (2003) al señalar el paradójico "anti-intelectualismo" militante de muchos intelectuales latinoamericanos (fundamentalmente escritores) que se radicalizaron hacia posiciones de acción directa y lucha armada en esos años, abandonando en el camino toda actividad que no fuera estrictamente política o subsumiendo todo proceso creativo a las demandas de la "lucha revolucionaria". Menos se ha estudiado lo sucedido dentro de las instituciones académicas y los ámbitos científicos aunque la tensión entre la construcción de espacios para la investigación y las demandas de la lucha política fue central en las discusiones entre los universitarios en ese momento. Sirva entonces el anterior señalamiento de los frenos internos de la Reforma Universitaria de los sesenta en Uruguay para matizar también la idea de que sólo el enfrentamiento con el poder político y el embate de las derechas explica lo sucedido en la Universidad en el lustro siguiente.

En esos años, efectivamente, los temas específicos de la política universitaria se fueron volviendo menos importantes y la reestructu-

25. Nuestra posición, Expediente caratulado Disidentes de FEUU, carpeta 3224, en Archivo de la Dirección Nacional de Información e Inteligencia (ADNII), Montevideo. Citado en Markarian (2012, pp. 76-77). ra académica dejó de ser un tema central en los organismos del cogobierno. Muchos de los asuntos que antes se habían resuelto en términos predominantemente académicos o administrativos se desviaron hacia discusiones de carácter netamente político e ideológico, mientras las reiteradas acciones represivas del gobierno, las disrupciones de cursos, las clausuras de locales y los incumplimientos presupuestales se volvían asuntos de todos los días. También el rector Maggiolo empezó a ver que su tiempo y energía se agotaban en lidiar con los conflictos con el Poder Ejecutivo y las continuas amenazas de violación de la autonomía universitaria. Para ese entonces, ya era claro que no había ni en el gobierno ni en la Universidad espacios para impulsar la discusión y generar acuerdos políticos con el fin de reestructurar la educación superior y promover el desarrollo de la ciencia y la tecnología en el país. Terminemos abruptamente esta historia diciendo que la situación siguió empeorando hasta que el régimen autoritario instalado con el golpe de Estado de 1973 intervino finalmente la casa de estudios y dio comienzo a un período de excepción en la vida universitaria que duró casi doce años (Markarian, 2015).

\section{Conclusiones}

En las páginas precedentes, hemos tratado de mostrar cómo las referencias a Córdoba (y el apelativo "reformista" por adscripción a ese legado) fueron adquiriendo nuevos significados $\mathrm{y}$ declinaciones entre los años cincuenta y sesenta del siglo pasado para los universitarios uruguayos. El texto de Maggiolo con que iniciamos el recorrido comenzaba por reconocer el aporte renovador de esa forma de pensar la vida universitaria para luego descartarlo, qui- 
zás con exagerado optimismo (a pesar del tono belicoso), como algo definitivamente superado. Parecería que la efectiva sanción de los principios más básicos generalmente asociados a esa tradición en la nueva Ley Orgánica de 1958 ponía de manifiesto todo lo que todavía quedaba pendiente para la generación que entonces ganó poder en el cogobierno. En un ambiente proclive a seguir transformando la institución, la crítica al legado cordobés se podía hacer abiertamente aunque adquiriera tintes beligerantes. No se trataba tanto de disputar el derecho a invocar a Córdoba como de posicionarse por encima de su herencia para exigir reformas que no solían asociársele, especialmente las relativas al lugar de la investigación científica en una estructura académica que se consideraba perimida. En un ambiente influido por las teorías de la modernización y el pensamiento desarrollista, cobraron fuerza los llamados a actualizar la vida académica de acuerdo al modelo de las instituciones terciarias de los países desarrollados. Consecuentemente, casi diez años más tarde, en 1967, cuando se logró efectivamente la articulación de un programa de transformación estructural en el "Plan Maggiolo", se optó por prescindir de las referencias a Córdoba que parecían demasiado atadas a una tradición académica, la predominante en la región, que se veía como inadecuada para los tiempos que corrían.

Pero en ese mismo momento, que fue, de alguna manera, de auge de la agenda de la llamada "generación reformista", que finalmente lograba poner a las políticas de actualización científica en el centro del debate universitario, el escenario nacional y regional volvió a plantear dudas sobre los logros más básicos de la década anterior, especialmente la autonomía y el cogobierno. Algunos actores universitarios, notoriamente dentro del movimiento estu- diantil, comenzaron a proclamar que ya era hora de alinear a las universidades con el horizonte revolucionario que Cuba había trazado en el continente. En ciertos casos, estos grupos frecuentemente concibieron los espacios académicos como meros campos de reclutamiento de adhesiones para sus proyectos políticos. En sus discursos, Córdoba reapareció como el origen mítico de un movimiento revolucionario truncado a nivel continental que era necesario finalizar por los medios que fuera (algo similar sucedió con el artiguismo a partir del revisionismo histórico de los movimientos independentistas del siglo XIX). Estas posturas chocaron con un gobierno nacional cada vez más autoritario y con sectores de las derechas políticas que ponían en cuestión los resultados de una década de participación estudiantil e independencia académica. Pero entraron en conflicto también con una parte importante de las autoridades de la institución y muchos de sus docentes más destacados que optaron por seguir defendiendo la autonomía relativa del campo universitario frente a esos embates.

Es interesante notar para terminar este recorrido que, en ese contexto, el apelativo "reformista" se despegó muchas veces de Córdoba y se tiñó de otros sentidos, especialmente en su referencia a las escisiones entre "revolucionarios" y "socialdemócratas" en Alemania a comienzos del siglo que todavía resultaban relevantes en las discusiones de la izquierda a nivel global. Así, "reformista" fue la repetida caracterización de los comunistas y sus aliados por parte de los grupos más radicales y el mote, igualmente descalificante, de muchos otros en la izquierda para todos aquellos que no propugnaran un cambio completo de las estructuras sociales en el sentido que cada uno definía como "verdadero" y "necesario", es decir "revolucionario". De todas esas tensiones y 
disputas por el significado de los términos políticos deriva, entonces, la relativa ironía de un rótulo que, por diferentes razones, casi todos asumieron a menudo a medias y muchas veces con prevenciones. Valga esa nota mordaz para resaltar otra deriva fundamental de una época que se abrió en América Latina con el impulso reformador, modernizante y orgullosamente democrático de la segunda posguerra y se cerró con la disyuntiva revolucionaria y la experiencia brutal del autoritarismo en toda la región.

Terminamos de esta manera un poco extemporánea, sólo para que no quepa ninguna duda acerca de que el estudio de las apelaciones a Córdoba como una tradición inequívocamente universitaria es una manera tangencial de indagar en los profundos cambios que sufrieron las instituciones de educación superior en América Latina en las dos décadas que venimos recorriendo. Podría ser también una puerta de entrada en los igualmente complejos procesos de recuperación institucional en las transiciones democráticas de los ochenta. No es claro, empero, qué pasa en la actualidad, cuando cualquier referencia a "la Reforma" despierta en seguida un reguero de dudas sobre la eficacia de ese legado para seguir explicando el presente y animando a pensar el futuro de las universidades latinoamericanas. ${ }^{26}$ Retomando las palabras del comienzo, la pregunta que queda abierta es si permanece vigente el "régimen de historicidad", es decir la forma de articular experiencias y expectativas que, por encima de sus diferencias, derivas y aún ambigüedades, pudimos rastrear en boca de los universitarios uruguayos de los cincuenta y sesenta del siglo

26. Por un ejercicio de indagación en las recurrencias de Córdoba en tres épocas bien diferentes de la política argentina en la segunda mitad del siglo veinte, incluyendo el período de recuperación democrática de los ochenta, véase: Requena (2017). pasado. Como ha señalado, entre otros, Hartog (2007), nuestra temporalidad parece sufrir de una inédita ampliación del presente, de modo que las referencias al pasado han perdido en gran medida su capacidad de prometernos un porvenir verosímil. En ese preciso sentido, estas páginas han tomado como ejemplo la mención de Córdoba en un puñado de documentos cuidadosamente elegidos no para rastrear hasta allí una supuesta genealogía de nuestras concepciones sobre la educación superior sino simplemente para alertar sobre el cambiante significado de la historia en el vocabulario político de cada época (y, por qué no, sobre su eventual obsolescencia). ${ }^{27}$

Recibido: 05-09-2018 Aceptado: 19-03-2019 Publicado: 04-06-2019

27.Este propósito está inspirado, como es obvio, en las propuestas de la llamada "historia conceptual". Véase, por ejemplo, Fernández (2014). 


\section{Referencias Bibliográficas}

Bagú, S. (1970). Hacia una politica cultural autónoma para América Latina. Montevideo: Departamento de Publicaciones de la Universidad de la República.

Beigel, F. (2006). La epopeya de una generación y una revista: Las redes editoriales de José Carlos Mariátegui en América Latina. Buenos Aires: Biblos.

Buchbinder, P. (2008). ¿¿Revolución en los claustros? La reforma universitaria de 1918. Buenos Aires: Sudamericana.

Cuadro Cawen, I. (2018). Unidad estudiantil y participación en el gobierno universitario: el Primer Congreso Internacional de Estudiantes Americanos en 1908. En V. Markarian (Ed.), Movimientos estudiantiles del siglo XX en América Latina (pp. 21-52). Rosario: HyA ediciones.

Fernández Sebastián, J. (2014). Historia, historiografía, historicidad: Conciencia histórica y cambio conceptual. En M. Suárez Cortina (Ed.), Europa del sur y América Latina: Perspectivas historiográficas (pp. 35-64). Madrid: Biblioteca Nueva.

Garcé, A. (2002). Ideas y competencia politica en Uruguay, 1960-1973: Revisando el "fracaso" de la CIDE. Montevideo: Trilce.

Gilman, C. (2003). Entre la pluma y el fusil: Debates y dilemas del escritor revolucionario en América Latina. Buenos Aires: Siglo XXI.

Hartog, F. (2007). Regimenes de bistoricidad: Presentismo y experiencia del tiempo, México: Universidad Iberoamericana.

Jung, M. E. (2013). De la Universidad del Norte a la Universidad para el desarrollo (1968-1970). Las posiciones de "las derechas" sobre el futuro de la educación superior. De la Universidad del Norte a la Universidad para el desarrollo, 1968-1970. Contemporánea, 4, 1-36. Recuperado de http://www.geipar. udelar.edu.uy/index.php/2017/05/06/maria-eugenia/

Jung. M. E. (2013). La UDELAR y la creación del CONICYT: Debates y conflictos (1961-1964). Encuentros Uruguayos 4(1), 32-49. Recuperado de http://www.encuru.fhuce.edu.uy/images/revistas/ revista-encuentros-2011-diciembre.pdf

Koselleck, R. (1993). Futuro pasado: Para una semántica de los tiempos históricos. Barcelona: Paidós, 1993.

Maggiolo, O. (2017). Plan de Reestructuración de la Universidad presentado por el rector de la Universidad Óscar J. Maggiolo, Montevideo, julio de 1967. Montevideo: Archivo General de la Universidad de la República.

Markarian, V. (2011). Apogeo y crisis del reformismo universitario: Algunos debates en torno al "plan Maggiolo” en la Udelar. Pensamiento Universitario, 14, 91-63. Recuperado de https:/www.academia. edu/13323278/PENSAMIENTO_UNIVERSITARIO_14

Markarian, V. (2015). La Universidad intervenida: Cambios y permanencias en la educación superior 
uruguaya durante la última dictadura (1973-1984). Cuadernos Chilenos de Historia de la Educación, (4). Recuperado de http://historiadelaeducacion.cl/index.php/CCHE/article/view/58

Markarian, V. (2014-2015). Un intelectual comunista en tiempos de guerra fría: José Luis Massera, matemático uruguayo. Políticas de la Memoria, (15).

Markarian, V.(2016). Universidad, revolución y dólares: Aproximación a otras discusiones de la izquierda uruguaya en los sesenta a partir de algunas polémicas generadas en la Facultad de Ingeniería y Agrimensura. Ponencia presentada en Intellectual Cultures of Revolution in Latin America: A Transnational Perspective, Instituto Mora/London School of Economics, México DF, México.

Markarian, V. (2012). El 68 uruguayo: El movimiento estudiantil entre cóckteles molotov y música beat. Bernal: Universidad Nacional de Quilmes.

Markarian, V., Jung, M. E. y Wschebor, I. (2008). 1958: El cogobierno autonómico. Montevideo: Archivo General de la Universidad de la República.

Martínez, M. L. (2001). La Asociación Uruguaya para el Progreso de la Ciencia. Galileo, (23). Recuperado de http://galileo.fcien.edu.uy/.

Oddone, J. y París, M. B. (1971). La Universidad uruguaya del militarismo a la crisis. Montevideo: Universidad de la República.

Petit Muñoz, E. (1961). El derecho de nuestra universidad a darse su propio estatuto. Montevideo: Editorial Ciencias.

Petra, A. (2008-2009). El Proyecto Marginalidad: Los intelectuales latinoamericanos y el imperialismo cultural. Políticas de la Memoria, (8-9), 249 - 260.

Requena, P. M. (2017). La larga vida del reformismo. Integración y conocimiento, 6(1), 41-52.

Rey Tristán, E. (2006). La izquierda revolucionaria uruguaya, 1955-1973. Montevideo: Fin de Siglo.

Ribeiro Coelho, H. (2002). O Exilio de Darcy Ribeiro no Uruguay. Aletria, 211-225. DOI: http://dx.doi. org/10.17851/2317-2096.9.0.211-225.

Ribeiro, D. (1968). La Universidad Latinoamericana. Montevideo: Universidad de la República.

Sessa, L. (2011). Semillas en tierras estériles: La recepción del APRA en la Argentina de mediados de la década de los treinta. Sociohistórica, (28), 131-161. Recuperado de https://www.sociohistorica.fahce. unlp.edu.ar/article/view/n28a05/290

Van Aken, M. (1990). Los militantes: Una bistoria del movimiento estudiantil uruguayo. Montevideo: Fundación de Cultura Universitaria. 